\title{
LA RELACIÓN ENTRE TRATADOS DE INVERSIÓN Y CONVENIOS DE DOBLE TRIBUTACIÓN: el caso chileno
}

\section{A RELAÇÃO ENTRE TRATADOS DE INVERÇÃO E CONVÊNIOS DE DUPLA TRIBUTAÇÃO: o caso chileno}

\author{
Rodrigo Polanco Lazo* \\ Felipe Yáñez Villanueva* *
}

\begin{abstract}
El presente artículo examina las relaciones entre los tratados de inversión y los tratados de doble tributación, considerando que, en la actual evolución de ambos tipos de acuerdos, sus disposiciones pueden presentar superposiciones en aspectos tales como estándares de protección, transparencia, trato nacional, cláusula de la nación más favorecida, expropiación y transferencias de capital. Tomando el ejemplo de los tratados suscritos por Chile, en este trabajo se examinan las consecuencias de las trasposiciones de ambos acuerdos, desde el punto de vista de sus mecanismos de solución de controversias, como en lo referido a los conflictos de jerarquía normativa entre esos dos tipos de tratados. Asimismo, se efectúa un análisis sobre iniciativas de tipo multilateral que afectan a ambas categorías de acuerdos como el Base Erosion and Profit Shifting (BEPS).

PALABRAS-ClavE: Inversión extranjera. Acuerdos bilaterales de inversión. Convenios de Doble Tributación. BEPS. Chile.
\end{abstract}

\section{MARCO GENERAL Y CONSIDERA- CIONES POLÍTICAS}

\section{La política chilena de suscripción de Con- venios para evitar la Doble Tributación (CDT) y Acuerdos Internacionales de Inver- sión (All)}

La experiencia chilena, como parte en Convenios para evitar la Doble Tributación (CDT) es relativamente reciente, comparada con la de otros países latinoamericanos como Brasil, Argentina o México. El primer CDT firmado por Chile fue negociado con Argentina en 1976, siguiendo el modelo del Pacto Andino (1971) y entró en vigor en 1986. Desde 1999, Chile se volvió más activo en la negociación y firma de CDT, principalmente basados en la convención modelo sobre la doble tributación de la renta y del capital de la Organización

* Universidade do Chile. Faculdade de Direito. Departamento de Direito Econômico.

Instituto Mundial do Comércio (WTI) da Universidade de Bern.rodrigo.polanco@wti.org

${ }^{* *}$ Universidade de Los Andes (Chile).

Diretor de tributação corporativa em Mazars Chile. felipe. yanez@mazars.cl para la Cooperación y el Desarrollo Económicos (Modelo Organisation for Economic Cooperation and Development - OCDE, 2014) y la convención modelo de las Naciones Unidas sobre la doble tributación entre países desarrollados y países en desarrollo (Modelo United $\mathrm{Na}$ tions - ONU, 2011). Actualmente, Chile tiene veintiséis CDT en vigor, mientras otros cinco se encuentran actualmente concluidos y están en espera de su ratificación parlamentaria (Servicio de Impuestos Internos, 2015).

Chile ha firmado cincuenta y tres Acuerdos de Promoción y Protección de Inversiones (APPI), pero solo treinta y siete de ellos se encuentran actualmente en vigor (United Nations Conference on Trade and Development, UNC$T A D$, 2015). Adicionalmente, Chile ha suscrito once Tratados de Libre Comercio (TLC) con un capítulo de Inversiones, nueve de ellos en vigor. En total, Chile tiene cuarenta y cuatro Acuerdos Internacionales de Inversión (AII) vigentes, un concepto que incluye tanto a los APPI como a los capítulos de inversión de los TLC, teniendo en cuenta que algunos de estos últimos reemplazaron previos tratados bilate- 
rales de inversión. ${ }^{1}$

Con la mayoría de los países que Chile ha firmado CDT también ha concluido AII. ${ }^{2}$ Sólo los CDT con Irlanda, Rusia y Tailandia no tienen un AII correspondiente. Sobre la base de estos datos, es posible afirmar que hay una criterio común para seleccionar Estados socios para CDT y para AII.

Un importante número de los AII suscritos por Chile han sido ratificados, y las ratificaciones pendientes son principalmente debido a las limitaciones o retrasos en la otra parte contratante, más que en el Congreso chileno. ${ }^{3}$ Del mismo modo, la gran mayoría de los CDT firmados han sido ratificados y sólo cinco están en espera de la ratificación en el Congreso. ${ }^{4}$ Se puede decir, en general, que el Congreso chileno no ratifica CDT a menos que tenga alguna certeza de que la otra parte contratante hará.

\section{¿Un modelo Chileno de Acuerdos Interna- cionales de Inversión (All) o de Convenios de Doble Tributación (CDT)?}

Actualmente, Chile no tiene un modelo oficial para negociar AII, aunque UNCTAD reporta que, a mediados de la década de los 90, mantenía un modelo de acuerdo bilateral de Inversiones (United Nations Conference on Trade and Development - UNCTAD, 1994) como parte de su estrategia de inserción internacional en esa década. Sin embargo, es posible distinguir algunos patrones que se reiteran en la - mayoría de los acuerdos suscritos por Chile:

ஓं 1 Estos son los APPI con China (1994), Corea del Sur (1996), Perú (2000) y Colombia (2000).

${ }^{2}$ Chile tiene CDT con Austria y Estados Unidos que todavía no están vigentes, aunque AII con ambos países ya

ô lo están. Chile también tiene CDT en vigor con Brasil y

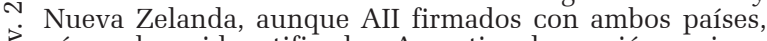

aún no han sido ratificados. Argentina denunció su primer

CDT con Chile el 29 de junio de 2012, y ambos países fir-

maron uno nuevo el 22 de abril de 2015 , el cual aún no ha $\frac{2}{\pi}$ sido ratificado. El APPI entre ambos países sigue vigente.

- ${ }^{3}$ Los APPI con Brasil (1994), Hungría (1997), Holanda (1998), Sudáfrica (1998), Túnez (1998), Turquía (1998), Egipto (1999), Indonesia (1999), Líbano (1999), Nueva Z Zelanda (1999) y Vietnam (1999) no han sido ratificados.

${ }^{4}$ Estos son los CDT con Estados Unidos (2010), Austria (2012), Sudáfrica (2012), China (2015) y Argentina (2015). cláusulas de no discriminación o estándares relativos, tales como el Trato Nacional (TN) o la Nación Más Favorecida (NMF); estándares absolutos, como el Trato Justo y Equitativo (TJE) o la Protección y Seguridad Plenas (PSP); acceso al mercado cambiario; libre transferencia de remesas asociadas a la inversión, incluyendo capital y utilidades; compensación, en caso de expropiación; y la posibilidad de solucionar controversias en contra del Estado receptor de la inversión, mediante arbitraje internacional (Polanco Lazo, 2012, p. 222-223).

Los capítulos de Inversiones de los TLC suscritos por Chile ya dan cuenta de la experiencia adquirida por el país en negociaciones previas y contienen textos más largos y complejos que los APPI, con descripciones detalladas de ciertas cláusulas, especialmente en lo referido a la extensión del TJE, expropiación indirecta y la definición de inversión. Estos capítulos también incluyen mecanismos de filtro para medidas impositivas, excepciones para ciertos sectores y reglas de transparencia. Sólo el APPI Chile-Uruguay (2010) sigue este modelo (Id., Ibid., p. 223).

Aunque Chile tampoco tiene un modelo oficial para la negociación de CDT, las autoridades chilenas han utilizado un formato basado en el modelo OCDE, con algunas variaciones inspiradas en el modelo ONU y otras derivadas del sistema impositivo chileno. Después de su accesión a la OCDE en 2010, Chile modificó parcialmente este modelo, al introducir normas sobre intercambio de información promovidas por la OCDE, la que se ha acordado en los tratados firmados con Australia, Austria y Estados Unidos, así como en el Acuerdo de Intercambio de Información Tributaria (AIIT) firmado con Uruguay (Exchange of Tax Information Portal, 2015). 


\section{RELACIÓN ENTRE TRATADOS IM- POSITIVOS Y ACUERDOS SOBRE INVERSIONES}

\section{Superposición entre Convenios de Doble Tributación (CDT) y Acuerdos Internaciona- les de Inversión (All)}

Muchos tratados de inversión no se refieren directamente a aspectos tributarios o guardan silencio a ese respecto. Cuando tratan materias impositivas, los AII normalmente se enfocan en preservar la autonomía fiscal, o reafirman la política impositiva exterior, excluyendo de su ámbito de aplicación a los CDT. Ciertos tratados excluyen de su alcance las materias impositivas en términos generales, o específicamente en disciplinas sobre no-discriminación. Con todo, un número creciente de AII incluye disposiciones referidas a impuestos, delimitando los casos en los cuales una medida tributaria puede tener características de expropiación, o estableciendo factores o procedimientos para determinarlo (Qureshi, 2015, p. 206-209, 213).

Debido a la falta de excepciones específicas o del carácter limitado de ciertas exclusiones en AII, algunas medidas tributarias podrían dar lugar a reclamaciones bajo estos mismos tratados. Los impuestos pueden ser caracterizados como una forma indirecta o progresiva de expropiación, o de beneficios discriminatorios en favor de determinados Inversionistas, lo que podría afectar disposiciones de AII referidas a expropiación y no discriminación (Park, 2009, p. 185). Ciertas medidas tributarias pueden también afectar otras disciplinas de AII, como el TJE o las denominadas cláusulas paraguas, por ejemplo, mediante la interpretación administrativa de la legislación impositiva o de contratos de inversión con cláusulas de estabilización tributaria (Qureshi, 2015, p. 211-213).

\section{Conflictos entre Acuerdos Internacionales de Inversión (All) y Convenios de Doble Tributación (CDT) suscritos por Chile}

Tal como se ha mencionado, existen al menos dos áreas donde pueden surgir conflictos entre tratados de Inversión y convenios de doble tributación: expropiación y no discriminación.

Con respecto a expropiación, algunos AII suscritos por Chile - principalmente los capítulos de Inversiones TLC - permiten la aplicación de sus cláusulas sobre compensación por expropiación, en el caso que una medida tributaria tenga un efecto equivalente a la expropiación. ${ }^{5}$ Conforme a estos tratados, si existe una disputa acerca del carácter expropiatorio de medidas tributarias, el Inversionista debe solicitar la resolución de este punto a las autoridades impositivas de los Estados Contratantes del AII. Estas autoridades pueden hacer una determinación vinculante sobre si la medida impugnada equivale a una expropiación. Sólo si no logran llegar a un acuerdo, después de un cierto período de tiempo (seis meses o 180 días), el asunto puede ser remitido a un tribunal arbitral. Este mecanismo de filtro sigue el modelo del Tratado de Libre Comercio de América del Norte (TLCAN), donde se introdujo por primera vez.

En la mayoría de los CDT chilenos, cuando un Inversionista considera que medidas estatales implican una imposición que no esté conforme con las disposiciones de ese tratado, los Inversionistas pueden utilizar un Procedimiento de Acuerdo Mutuo (PAM), presentando su caso a la autoridad competente del Estado Contratante del que sea residente o, en los casos de no-discriminación que impliquen una vulneración de la garantía de trato nacional, a la autoridad del Estado Contratante del que sea nacional. En ambos casos, el plazo para efectu${ }^{5}$ El Protocolo de la Alianza del Pacífico (2014), el Acuerdo Suplementario sobre Inversiones ente Chile y China (2012), y los TLC con Australia (2008), Japón (2007), Colombia (2006), Perú (2006), Corea del Sur (2003), Estados Unidos (2003), México (1998) y Canadá (1996). También se encuentra en el APPI con Uruguay (2010). 
ar la presentación es de tres años a partir de la primera notificación de la medida que implique una imposición no conforme a las disposiciones del CDT (Organisation for Economic Cooperation and Development, 2014, art. 25). En estos casos, la autoridad competente deberá resolver la cuestión mediante un acuerdo mutuo con la autoridad competente del otro Estado contratante, sin un plazo concreto para adoptar una decisión.

Un conflicto entre un AII y un CDT podría surgir si una medida tributaria es impugnada por considerarse equivalente a una expropiación, conforme a lo establecido en el AII, y las autoridades fiscales competentes no llegan a un acuerdo sobre el tema dentro del plazo establecido, dejando que esa decisión sea adoptada por el tribunal en un arbitraje Inversionista-Estado. Esa decisión arbitral puede ser diferente a la de las autoridades fiscales competentes si el mismo reclamo se inicia conforme a las cláusulas de un CDT.

Asimismo, algunas medidas tributarias podrían encontrarse tanto bajo el ámbito de aplicación de un AII como de un CDT, en materias referidas a no-discriminación. Mientras que los AII chilenos contienen regularmente normas de protección en este sentido, como el TN y la cláusula de la NMF, los CDT chilenos también suelen incluir disposiciones en • ese ámbito, garantizando el TN en materia de $\underset{\sim}{\sim}$ imposición aplicable a las personas físicas $\mathrm{y}$ i empresas. Así, una medida tributaria que discrimina a un Inversionista extranjero puede ser caracterizada, a la vez, como una violación \% de un AII y de un CDT, lo que podría gatillar, al ris mismo tiempo, un arbitraje Inversionista-Esta$\dot{d}$ do y un PAM, en los cuales se pueden generar os diferentes interpretaciones.

La situación puede volverse aún más compleja, si consideramos que ni los AII ni los CDT consideran una definición de que se entiende por impuesto o medida tributaria.

\section{Disposiciones especiales de Acuerdos In- ternacionales de Inversión (All) aplicables en caso de conflicto con Convenios de Doble Tributación (CDT)}

Los APPI chilenos generalmente guardan silencio sobre esta materia, la que se encuentra regulada con frecuencia en los capítulos de inversión de los TLC. Dichos tratados establecen que, en caso de cualquier discrepancia relativa a una medida tributaria entre el tratado y un CDT, éste último prevalecerá. Sólo el APPI con Uruguay (2010) contiene una disposición similar.

El Acuerdo Complementario con China, los TLC con Australia, Colombia y Estados Unidos, y el APPI con Uruguay añaden que las autoridades fiscales competentes, en virtud del CDT, tendrán la exclusiva responsabilidad de determinar si existe alguna inconsistencia entre ambos tratados.

El TLC con Japón es menos explícito en este sentido, estableciendo simplemente que nada en ese acuerdo "afectará a los derechos y obligaciones de cualquiera de las Partes en virtud de las disposiciones relativas a las medidas fiscales en otros acuerdos internacionales de los que ambas Partes sean parte". ${ }^{6}$

\section{Solución de controversias entre Acuerdos Internacionales de Inversión (AlI) y Conve- nios de Doble Tributación (CDT) en ausen- cia de normas especiales}

En ausencia de una cláusula especial, si surge una controversia acerca de la aplicación entre ambos tratados, en los AII donde un mecanismo de filtro ha sido establecido, el conflicto será probablemente resuelto mediante el acuerdo de las autoridades fiscales competentes, un mecanismo que es un reflejo del PAM de los CDT. Es esperable que las autoridades competentes del Estado de origen del Inversionista no estén de acuerdo con el arbitraje,

${ }^{6}$ Chile - Japón TLC, Art. 194.2. 
a menos que las medidas impugnadas "estén destinadas a operar de facto como expropiación en vez de un mecanismo legítimo de percepción de ingresos.” (Park, 2009, p. 194).

Es más probable que surjan problemas tratándose de Acuerdos APPI, dado que, por lo general, no cuentan con mecanismos de filtro para determinar si una medida tributaria es equivalente a una expropiación. Los AII progresivamente incluyen disposiciones con el fin de aumentar la previsibilidad de la definición de expropiación, proporcionando orientación en relación con la expropiación indirecta y reafirmando "el derecho a regular”, estableciendo una serie de limitaciones y requisitos para la expropiación, para preservar objetivos políticos del Estado receptor (United Nations Conference on Trade and Development UNCTAD 2012, 125)

Actualmente, no existe jurisprudencia sobre disputas entre la aplicación de AII y CDT chilenos.

\section{Conflictos entre Acuerdos Internacionales de Inversión (AlI) y otros tratados o acuer- dos que contienen disposiciones tributarias}

No existe información sobre conflictos entre AII y otros acuerdos suscritos por Chile que contengan disposiciones fiscales. La razón más probable para ello es que, aparte de los CDT, el único tratado celebrado por Chile que contiene cláusulas referidas a impuestos es la Convención de la OCDE sobre Asistencia Administrativa Mutua en Materia Fiscal, un tratado que se centra en asuntos de cooperación fiscal para hacer frente a la evasión fiscal y elusión tributaria, y no en los derechos sustantivos de las personas jurídicas o naturales, acuerdo que además aún no está en vigor (OCDE, 2016).7 Chile tampoco ha sido uno de los primeros países en adoptar el acuerdo multilateral que implementa el estándar OCDE sobre intercambio automático de información (OCDE, 2014).

${ }^{7}$ Chile firmó la versión enmendada de esa Convención (2010) el 24 de octubre de 2013.
Conflictos entre Convenios de Doble Tributación (CDT) y otros tratados internacionales que protegen la inversión extranjera

Con el fin de evitar conflictos de interpretación entre CDT y otros tratados, la gran mayoría de los APPI chilenos contiene una disposición que establece que, si una Parte Contratante otorgar ventajas especiales a los Inversionistas de cualquier tercer país, y sus Inversiones, en virtud de un acuerdo que establezca un área de libre comercio, una unión aduanera, un mercado común o una unión económica o un acuerdo multilateral sobre Inversiones al que la Parte actualmente pertenece o en el futuro puede pertenecer, o por medio de las disposiciones de cualquier acuerdo internacional, arreglo internacional o legislación nacional en relación con tributación, el Estado no estará obligado a conceder las referidas ventajas a los Inversionistas de la otra Parte Contratante y a sus Inversiones.

Los capítulos de Inversiones de TLC chilenos no incluyen una disposición relativa a los conflictos con CDT u otros tratados de inversión.

\section{TRATADOS DE INVERSIÓN E IM- PUESTOS}

Como ya se ha señalado, las medidas tributarias generalmente no se encuentran de manera expresa dentro del ámbito de aplicación de los AII chilenos. Sin embargo, aun cuando los tratados de inversión no tengan por objeto crear derechos en materia impositiva para los inversionistas extranjeros, ellos proveen ciertos derechos y estándares para todo tipo de tratamiento por parte del Estado receptor de la inversión extranjera, que pueden ser asociados con tributación y administración fiscal, a menos que esos asuntos hayan sido expresamente excluidos del ámbito de protección del AII (Vanderbruggen, 2013, p. 7). 


\section{Exclusiones}

En AII, la preservación de la política tributaria a nivel interno y exterior se asegura mediante dos tipos de exclusiones: las que consideran la autonomía impositiva a nivel nacional y las que contemplan evitar conflictos con acuerdos internacionales de tributación (Qureshi, 2015, p. 214). Los AII chilenos consideran ambos tipos de exclusiones.

\section{Autonomía Tributaria a Nivel Nacional}

Las exclusiones sobre autonomía impositiva dicen relación principalmente con determinar si los principios de la aplicación de los principios de TN y cláusula NMF) se aplican a las medidas tributarias.

Sólo los APPI con Dinamarca y Austria excluyen expresamente la aplicación de la cláusula NMF con respecto a las medidas tributarias, estableciendo que una Parte Contratante no está obligada a extender las ventajas fiscales entregadas, en virtud de otros acuerdos internacionales, a los inversores de la otra Parte Contratante y a sus Inversiones. El APPI con Dinamarca también excluye el TN, ya que una parte contratante no está obligada a extender los beneficios considerados en la legislación fiscal nacional a los inversores de la otra parte contratante. Otra excepción a este respecto es el APPI con Uruguay, que sigue el modelo de los TLC chilenos.

$\mathrm{Al}$ contrario, los TLC chilenos con capítulos de inversión, por regla general, establecen que ninguna parte del tratado se aplicará a las medidas impositivas, y, por lo tanto, excluyen efectivamente las leyes tributarias de la aplicación de las cláusulas TN y NMF, las que, en estos acuerdos, se refieren sólo al establecimiento, adquisición, expansión, administración, conducción, operación y venta u otra disposición de las Inversiones en el territorio del Estado receptor.

Pero las disposiciones sobre tributos, en los AII, contienen esquemas de protección que consideran excepciones a las excepciones que dificultan la comprensión del ámbito de aplicación del acuerdo (Park, Arbitrability and Tax, 2009, p. 189).

Una exclusión parcial contempla el TLC con Australia, donde se establece que las normas de TN y NMF de su capítulo de Inversiones se aplican a la tributación, pero solo en caso de impuestos indirectos. Otras exclusiones son consideradas en los TLC con Canadá, Colombia y Estados Unidos y en el Protocolo de la Alianza del Pacífico, estableciendo que las disposiciones de sus capítulos de inversión referidas a TN y NMF se aplicarán a todas las medidas tributarias, distintas de aquellas sobre la renta, ganancias de capital o sobre el capital gravable de empresas, impuestos sobre el patrimonio, sucesiones, donaciones ${ }^{8} \mathrm{y}$ transferencias con salto de generaciones.

Adicionalmente, todos los TLC antes mencionados establecen que sus disposiciones sobre TN y NMF no se aplican a los beneficios otorgados en virtud de un convenio tributario, a una disposición disconforme o a los cambios efectuados a medidas tributarias existentes, así como a cualquier nueva medida tributaria encaminada a garantizar la imposición o recaudación equitativa y eficaz de los impuestos.

Los TLC con Australia, Colombia y Estados Unidos también incluyen, como parte de las excepciones a la aplicación de las normas NT y NMF en materia impositiva, una disposición que condiciona la obtención de una ventaja o que se continúe obteniendo la misma, con relación a las contribuciones a, o las rentas de, planes o fondos de pensiones, siempre que la Parte mantenga una jurisdicción permanente sobre el plan o fondos de pensiones. El TLC con Estados Unidos agrega, como otra excepción, cualquier impuesto especial sobre las primas de seguro adoptadas por Chile, en la medida en que tal tributo, si fuese impuesto por los Estados Unidos, se consideraría como cubierto por medidas tributarias existentes.

\section{Autonomía Tributaria a Nivel Internacional}

Generalmente, los APPI chilenos ex-

${ }^{8}$ La exclusión sobre donaciones no se encuentra en el TLC con Colombia ni en el Protocolo de la Alianza del Pacífico. 
cluyen expresamente los beneficios otorgados en CDT de la aplicación de la cláusula NMF. Un número limitado de APPI también excluye los beneficios tributarios otorgados en CDT de la aplicación del trato nacional. ${ }^{9}$

Los capítulos de Inversiones de los TLC chilenos no establecen expresamente una exclusión en esta materia, pero señalan que ninguna disposición de ese acuerdo afectará a los derechos y obligaciones de cualquiera de las Partes en virtud de cualquier convenio tributario. Lo mismo se establece en el APPI Chile-Uruguay.

\section{Cláusulas paraguas}

Como regla general, los AII chilenos no incluyen cláusulas paraguas. ${ }^{10}$ Estas no se consideran en los capítulos de inversión de los TLC suscritos por Chile, y solo unos pocos APPI las contemplan en sus textos: los acuerdos con Dinamarca, Grecia, Austria y Holanda (Yannaca -Small, 2006, p. 6, 11, 23-26). En estos casos, las cláusulas tributarias contenidas en contratos de inversión quedarían, en teoría, cubiertas por el APPI, conforme a su cláusula paraguas.

Sin embargo, no hay conflictos públicamente conocidos respecto a cláusulas paraguas en relación con disposiciones relacionadas con impuestos en AII chilenos.

\section{TRATO NACIONAL Y TRATO DE LA NACIÓN MÁS FAVORECIDA}

\section{En tratados de Inversión}

Las cláusulas de TN y NMF, en los APPI chilenos, generalmente estipulan que una par-

\footnotetext{
${ }^{9}$ Este es el caso de los tratados bilaterales con Alemania, Ecuador, Francia, Islandia, Italia, España, Reino Unido y Suecia.

${ }^{10}$ Se denominan cláusulas paraguas a aquellas disposiciones de los AII que obligan a los Estados signatarios a cumplir compromisos contraídos con respecto al Inversionista o la inversión fuera del tratado de Inversiones, como, por ejemplo, en un contrato (Mereminskaya Julio - Diciembre 2009, 13).
}

te contratante otorgará a las Inversiones de los Inversionistas de otra parte contratante, en su territorio, un trato no menos favorable que el otorgado a las Inversiones realizadas por sus propios Inversionistas o por aquellos de un tercer país. La mayoría de los APPI chilenos no contemplan circunstancias fácticas en su definición de TN y NMF, entregando una descripción amplia y sin criterios de comparación. Sólo los APPI con Austria y Portugal y los capítulos de libre comercio de TLC se refieren a "circunstancias similares” (Arrese Ortíz, 2009, p. 89).

La redacción de las cláusulas NMF, en la gran mayoría de los APPI suscritos por Chile, es tan amplia que puede permitir al Inversionista extranjero elegir selectivamente ciertas disposiciones específicas de otro tratado de Inversiones chileno, tanto en materia sustantiva como de solución de controversias, sin necesariamente "importar" las restricciones que no son más favorables de ese mismo acuerdo, como serían excepciones generales o exclusiones en determinadas materias. Aunque los TLC chilenos con capítulos de inversión tienen una redacción menos amplia de las cláusulas NMF, la elección selectiva también sería posible si se trata de actividades relacionadas con el establecimiento, adquisición, expansión, administración, conducción, operación y venta de una inversión.

Aunque todos los AII chilenos incluyen clausulas sobre TN y NMF, existen pocos casos en los cuales se haya resuelto acerca de la aplicación de estas disposiciones. En el caso MTD versus Chile, ${ }^{11}$ el demandante argumentó que Chile incumplió la obligación de TJE al fomentar fuertes expectativas de que un proyecto de inversión podría ser construido en una ubicación específica y, posteriormente, rechazar su localización, al oponerse a efectuar el cambio de uso de suelo como una cuestión de política pública, después de que el deman${ }^{11}$ MTD Equity Sdn. Bhd. and MTD Chile S.A. v. Republic of Chile, ICSID Case No. ARB/01/7, Laudo, 25 mayo 2004. Al menos que se indique lo contrario, todos los casos sobre arbitraje de Inversiones citados en este trabajo se encuentran disponibles en Investment Treaty Arbitration, http:// www.italaw.com/. 
dante ya había comprometido sustancialmente los recursos para el proyecto. Chile negó haber vulnerado la obligación de TJE, y alegó que había actuado de conformidad con sus leyes nacionales y la política urbana en negarse a conceder el cambio de uso de suelo. Dando un amplio alcance a la cláusula de NMS en este caso, el tribunal confirmó la petición de la demandante de utilizar la cláusula NMF del APPI Chile-Malasia para importar las disposiciones sobre TJE de los APPI Chile-Croacia y ChileDinamarca (Salomon; Friedrich, 2013, p. 2). ${ }^{12}$

Otro caso relevante se refiere a un impuesto adicional del $85 \%$ aplicable a las importaciones de vehículos cuyo valor supera los USD\$ 15.834 (conocido como impuesto de lujo, anteriormente establecido en el Art. 46 de la Ley del IVA de Chile), que fue calificada como una medida discriminatoria, de conformidad a la cláusula de TN incluida en el TLC con Canadá (1997) ${ }^{13}$ y que también se repite en los TLC con México y Estados Unidos. En razón de ello, dicho impuesto fue derogado por el Congreso chileno en 2003, con el fin de evitar más demandas por discriminación de parte de empresas fabricantes de automóviles basadas en los Estados Unidos, así como también en la Unión Europea. La eliminación de este tributo se hizo de manera progresiva, hasta dejar de aplicarse definitivamente el año 2007. ${ }^{14}$

Como generalmente los APPI no ex-

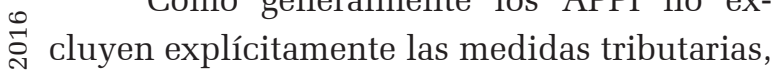
$\therefore$ se debe considerar que estas se encuentran incluidas en el alcance de las disposiciones sobre TN y NMF. Sin embargo, debemos recordar \& que la mayoría de los capítulos de inversión de 됟 TLC chilenos y el APPI con Uruguay excluyen \& explícitamente las medidas tributarias de su iิ campo de aplicación, excepto cuando son aplicables exclusiones en los términos que ya se ha explicado anteriormente.

${ }^{12}$ MTD v. Chile, Laudo, §104, 197.

${ }^{13}$ Corte Suprema de Chile, fallo de 1 abril de 2003, causa rol 375-2003, "Ditec Limitada Contra Administración Aduana Osorno".

${ }^{14}$ Ley $N^{\circ} 19.914$, publicada en el Diario Oficial de 19 de noviembre de 2003 .

\section{En tratados tributarios}

En la mayoría de los CDT chilenos, los nacionales de un estado contratante no serán sometidos en el otro estado contratante a ningún impuesto u obligación relativo a la misma, que no se exija o que sea más gravosa que aquellas a las que estén o puedan estar sometidos los nacionales de ese otro Estado que se encuentren en las mismas condiciones, en particular con respecto a la residencia. Además, los establecimientos permanentes que una empresa de un estado contratante tenga en el otro estado contratante no serán sometidos, en ese otro estado, a una imposición menos favorable que las empresas de ese otro estado que realicen las mismas actividades en circunstancias similares. ${ }^{15}$ En ese sentido, el alcance del TN en los CDT es muy similar al contenido en los APPI chilenos.

Ciertos CDT chilenos incluyen cláusulas NMF, como los tratados celebrados con Brasil, Canadá, Corea del Sur, Dinamarca, Ecuador, México, Noruega y Polonia, las que se refieren principalmente a cuestiones sustantivas, principalmente al impuesto de retención en la fuente, aplicable a los intereses y regalías. Sin embargo, esto no es una cláusula estándar de los tratados tributarios chilenos, como ocurre con sus tratados de inversión, al encontrarse considerada en todos ellos.

Hasta ahora, no se han registrado casos o conocido laudo donde medidas relacionadas con impuestos se hayan analizado a la luz de las cláusulas TN o NMF en los AII chilenos. Ello se debe probablemente al hecho de que los tratados de inversión chilenos no incluyen beneficios específicos solamente aplicables a nacionales chilenos ni a nacionales de terceros países que puedan ser incompatibles con las cláusulas TN o NMF de otros AII suscritos por Chile. Por otra parte, el derecho de no discriminación con respecto a las medidas tributarias también está consagrado en el art. $19 \mathrm{~N}^{\circ}$ 22 de la Constitución Chilena.

${ }^{15}$ Véase entre otros, Australia - Chile CDT, Art. 24. 


\section{TRATO JUSTO Y EQUITATIVO}

\section{En tratados de Inversión}

Aunque todos los AII chilenos incluyen una cláusula de TJE, existen diferencias importantes en cuanto a su contenido. La mayoría de los capítulos de inversión de sus TLC - y el APPI con Uruguay - define este estándar de una manera restrictiva, como parte del nivel mínimo de trato conforme al derecho consuetudinario internacional, sin crear derechos sustantivos adicionales ni requerir un tratamiento adicional o más allá de aquél exigido por ese nivel. De esta manera, la obligación de TJE generalmente incluye la obligación de no denegar justicia en procedimientos criminales, civiles o administrativos de conformidad con el principio de debido proceso incorporado en los principales sistemas jurídicos del mundo. ${ }^{16}$ Solo los TLC con Canadá y México no contienen una delimitación de esta cláusula, ni una referencia al derecho consuetudinario internacional. Con todo, el año 2002, la Comisión de Libre Comercio del TLC con Canadá emitió una nota de interpretación en la cual se considera el contenido del TJE como parte del mínimo estándar internacional ${ }^{17}$, en los mismos términos formulados el año precedente por la Comisión de Libre Comercio del TLCAN). ${ }^{18}$

En el caso de los APPI - salvo en el tratado con Uruguay - generalmente no está definido lo que se entiende por trato "justo" y "equitativo", pudiendo derivarse elementos que lo conforman de la ubicación de la cláusula en el texto del tratado, o de su relación con el

${ }^{16}$ El Art. 6 del Acuerdo Suplementario sobre Inversiones entre Chile y China también establece que el concepto de TJE debe interpretarse no más allá del nivel mínimo de trato de conformidad con el derecho internacional, pero sin efectuar una definición precisa de su contenido.

17 Canada - Chile Free Trade Commission, "Notes of Interpretation of Certain Chapter G Provisions," October 31, 2002, http://www.international.gc.ca/trade-agreements-accords-commerciaux/agr-acc/chile-chili/ccftacommission. aspx?lang $=$ eng.

${ }^{18}$ North American Free Trade Agreement (NAFTA) - Free Trade Commission, "Notes of Interpretation of Certain Chapter 11 Provisions," July 31, 2001, http:/www.international.gc.ca/trade-agreements-accords-commerciaux/ topics-domaines/disp-diff/NAFTA-Interpr.aspx. derecho internacional. Los APPI chilenos normalmente contienen esta cláusula, ya sea junto a las disposiciones referidas al tratamiento debido a las Inversiones (e. g. prohibición de medidas discriminatorias, irrazonables e injustificadas), o junto a los artículos referidos a la APPI (e. g. tratamiento de conformidad con la legislación nacional). Arrese estima que lo razonable sería concluir, en estos casos, que el estándar de TJE significa algo más que la abstención de esas conductas, de lo contrario su mención sería redundante (Arrese Ortíz, 2009). Por otra parte, este grupo de tratados no contienen una referencia expresa al derecho internacional para determinar el contenido de la cláusula TJE, salvo en el caso de los APPI con Francia y Bélgica, los que, sin embargo, no clarifican su relación con el estándar mínimo internacional. ${ }^{19}$

La falta de claridad acerca del alcance de este estándar puede interpretarse como una delegación a los tribunales arbitrales para interpretar su contenido. Al respecto, el primer caso que involucró un APPI chileno donde una cláusula TJE fue interpretada es MTD versus Chile. En su laudo, el tribunal arbitral determinó que la aprobación de una inversión de un proyecto por el Comité de Inversiones Extranjeras (CIE), ${ }^{20}$ que estaba en contra de la política urbana del gobierno, incumplió la obligación de tratar al Inversionista de manera justa y equitativa. ${ }^{21}$ La decisión se refiere a la falta de coherencia de la acción entre dos ramas del mismo Estado respecto del mismo Inversionista, resolviendo que la obligación de TJE es de carácter pro-activa, interpretando ese estándar de tratamiento de la manera más conducente para cumplir el objetivo del APPI de proteger a los Inversionistas y crear condiciones favorables para las Inversiones, en lu${ }^{19}$ Ibid., 65.

${ }^{20}$ El CIE, establecido por el DL 600 de 1974, fue derogado a partir del 1 de enero de 2016, por el Artículo 9 de la Ley $\mathrm{N}^{\circ}$ 20.780, publicada en el Diario Oficial del 29 de septiembre de 2014. En su reemplazo, la Ley $N^{\circ} 28.848$, publicada en el Diario Oficial del 25 de junio de 2015, estableció una Agencia de Promoción de la Inversión Extranjera (APIE).

${ }^{21}$ MTD v. Chile, Laudo, 25 mayo 2004, § 163-166, 189. 
gar de instrucciones que implican un comportamiento pasivo del Estado o evitar conductas perjudiciales para los Inversionistas. ${ }^{22}$

El otro arbitraje de Inversiones en el que Chile ha sido condenado por vulnerar el estándar TJE es el caso Pey Casado versus Chile. En esta disputa, referida a la expropiación del periódico chileno El Clarín luego del golpe militar del 11 de septiembre de 1973, el tribunal arbitral concluyó que no cometer denegación de justicia es parte de las diferentes obligaciones cubiertas por la norma TJE en el APPI Chile-España. Dos conductas fueron calificados como tales: la ausencia de una decisión de los tribunales chilenos, por un período de siete años, en un proceso para la recuperación de una máquina de impresión confiscada ${ }^{23}$ y el hecho de que la compensación por la expropiación de la propiedad del periódico fue concedida a personas que no eran dueñas de los bienes confiscados. ${ }^{24}$

Sin embargo, ni el caso MTD, ni el caso Pey Casado han tenido un impacto práctico sobre normas fiscales o la práctica administrativa en materia tributaria de Chile, dado que se refieren a materias ajenas a la órbita impositiva. Con todo, algunas prácticas llevadas a cabo por las autoridades tributarias chilenas o incluso algunos procedimientos aplicados en el pasado por los tribunales tributarios de Chile pueden considerarse como contrarios al principio de TJE consagrado en los AII.

Uno de ellos es el uso indebido por parte de la administración tributaria chilena de su facultad de solicitar a los contribuyentes la \& presentación de declaraciones juradas sobre 될 hechos, fechas o información de fondo en rea lación con terceros (artículo 60 del Código Triof butario de Chile). En el ejercicio de tal poder, que fue concebido como un instrumento específico para obtener información de los contri${ }^{22}$ Ibid. 1113.

${ }^{23}$ Víctor Pey Casado and President Allende Foundation v. Republic of Chile, ICSID Case No. ARB/98/2. Laudo, 8 Mayo 2008, Investment Treaty Arbitration, §659-664.

${ }^{24}$ Ibid. §665-673. buyentes, la administración tributaria chilena ha construido gradualmente una amplia red de fuentes de información relacionadas con los contribuyentes. De hecho, hace veinte años, las autoridades tributarias chilenas solicitaban no más de 20 declaraciones juradas referidas a información sobre terceros. ${ }^{25}$ En contraste, para el año fiscal 2015, el número de declaraciones juradas ascendió a más de $70 .{ }^{26}$ Como resultado, tal sistema de verificación cruzada permite la administración tributaria verificar la exactitud de las declaraciones de impuestos anuales presentados por cualquier contribuyente.

Al hacerlo, las autoridades tributarias chilenas obligan a muchos contribuyentes a revelar una gran cantidad de información comercial relacionada con terceros, quienes no tienen recursos legales directos para impedir o restringir dicha solicitud de la administración tributaria, incluso en los casos en que dicha información podría ser calificada como confidencial y, por lo tanto, cubierta por un deber de confidencialidad. El ejemplo más destacado de este tipo de prácticas se refiere a la solicitud formulada por las autoridades tributarias chilenas a los bancos comerciales para obtener información relacionada con la totalidad de las transferencias de dinero transfronterizo realizados por sus clientes por un monto superior a los USD \$10.000, lo que implica - hasta cierto punto - una infracción de las normas de secreto bancario vigentes. ${ }^{27}$

El antiguo régimen de litigación tributaria era otro prominente caso donde la ley impositiva chilena contenía normas que no satisfacían las reglas del debido proceso. Según ${ }^{25}$ SII, "Instrucciones Detalladas para la Confección de Declaraciones Juradas A.T. 2000”, http://www.sii.cl/declaraciones_juradas/suplemento/2000/anexo_c2000.htm, vista el $24 / 08 / 2015$.

${ }^{26}$ SII, "Instrucciones Detalladas para la Confección de Declaraciones Juradas A.T. 2015”, http:/www.sii.cl/declaraciones_juradas/suplemento/2015/anexo_c2015.htm, vista el $24 / 08 / 2015$.

27 SII, "Resolución Exenta SII N 120 del 31 de diciembre del 2004”, http://www.sii.cl/documentos/resoluciones/2004/reso120.htm, vista el 24/08/2015. Esta resolución es aplicable a las "remesas, pagos o traslados de fondos al exterior, ingresos de fondos desde el exterior u operaciones que impliquen disposición de fondos en el exterior",, vista el 24/08/2015. 
este régimen, que comenzó a ser reemplazado gradualmente por uno nuevo el año 2011, las disputas entre el Estado y los contribuyentes eran resueltas, en primera instancia, por un funcionario de la administración tributaria chilena, que estaba subordinado directamente al Director Nacional de ese organismo público $\mathrm{y}$, en consecuencia, dicho funcionario se encontraba obligado a seguir la opinión del Director Nacional del SII al momento de decidir litigios tributarios. Como resultado de ello, el juez carecía de imparcialidad para resolver esos conflictos (Greiber Betsalel; Ocampo Moscoso; Seguel Malagueño, 2007)

\section{En tratados tributarios}

No existen disposiciones que expresamente consideren el TJE en tratados tributarios chilenos. Sin embargo, tal como se ha mencionado, los CDT suscritos por Chile siguen, en general, el Modelo de la OCDE, pero con algunas diferencias que se han reflejado en sus reservas sobre el artículo 24 de dicho modelo. Las diversas disposiciones del artículo 24 impiden diferencias en el tratamiento fiscal que se basan únicamente en determinados motivos específicos (por ejemplo, la nacionalidad, el carácter de apátrida, situs real de una empresa, deducción de gastos). Son precisamente estas disposiciones las que pueden considerarse al menos parcialmente equivalentes al TJE.

El Artículo 24 (1) del Modelo OCDE establece que la discriminación por motivos de nacionalidad está prohibida, y que, en condiciones de reciprocidad, los nacionales de un estado contratante no pueden ser tratados de manera menos favorable en el otro estado contratante que los nacionales de este último estado, en las mismas circunstancias, en particular con respecto a la residencia. Este tratamiento no está limitado únicamente a los nacionales que sean residentes de un estado contratante, sino que se extiende a todos sus nacionales, sean o no sean residentes de uno de ellos. Chi- le ha reservado su posición en lo que se refiere a su aplicación a las personas que no sean residentes en uno o ambos de los estados contratantes. A pesar de ello, ciertos CDT chilenos incluyen una disposición de este tipo, como los tratados con Bélgica, Corea del Sur, España, Portugal, y Suiza. El resto de la redacción del artículo 24 (1), en la mayoría de los tratados de Chile, es la misma que la del modelo de la OCDE, por lo que este párrafo se aplica tanto a empresas y particulares. Una excepción es el CDT con Francia, donde se dice expresamente que sólo es aplicable a individuos, como resultado de la reserva formulada por Francia sobre el modelo de la OCDE en este párrafo (Madariaga Montes; Yáñez Villanueva, 2012)

El Artículo 24 (2) del Modelo OCDE extiende a los apátridas la misma protección que la concedida a los residentes. Los orígenes de dicha disposición se remontan al 28 de septiembre de 1954, cuando un grupo de Estados concluyó, en Nueva York, una Convención sobre el estatuto de los apátridas, según la cual ellos deben recibir trato nacional. Chile se ha reservado el derecho de insertar el artículo 24 (2) en sus CDT, ya que no ha ratificado la Convención de Nueva York. De hecho, esta disposición no encuentra en ningún CDT chileno vigente.

El Artículo 24 (3) del Modelo OCDE establece que la tributación de un Establecimiento Permanente (EP) no será gravada menos favorablemente en un estado contratante que las aplicables a empresas de ese estado que realicen las mismas actividades. El tipo de discriminación que se busca poner fin es una discriminación basada no en la nacionalidad, sino en el situs real de una empresa. El propósito de esta cláusula es poner fin a toda forma de discriminación en el tratamiento de los EP, en comparación con las empresas residentes que pertenecen al mismo sector de actividad, en cuanto a los impuestos sobre la base de las actividades empresariales, y especialmente los impuestos sobre sus beneficios. ${ }^{28}$ En todos ${ }^{28}$ OECD, Commentaries on the Articles of the Model Tax Convention, [8. ed.], condensed version 2010 (Amster- 
CDT, Chile ha reservado el derecho de mantener su capacidad de gravar tales establecimientos de acuerdo a su legislación nacional, teniendo en cuenta que la legislación chilena considera un impuesto sobre las utilidades de negocios (Impuesto de Primera Categoría), que es también aplicable a establecimientos permanentes que distribuyen sus utilidades al exterior. Aunque no sea un impuesto sobre los beneficios de una sucursal, sus características son similares y el hecho de que esto se menciona expresamente en todos los CDT significa que Chile va a imponer este impuesto no obstante la cláusula de no discriminación (Madariaga Montes; Yáñez Villanueva, 2012). Lo anterior se confirma en la observación de Chile al artículo 24 (3) del Modelo de la OCDE, donde señala que "en vista de su régimen fiscal especial, Chile mantiene su libertad de acción en relación con las disposiciones del tratado relativas a la tasa y forma de distribución de utilidades por establecimientos permanentes”. ${ }^{29}$ Los CDT con Canadá y Estados Unidos incluyen una disposición específica sobre los impuestos aplicables a los beneficios de las sucursales en esos países. ${ }^{30}$

El Artículo 24 (4) del Modelo OCDE está diseñado para poner fin a una forma particular de discriminación, como resultado del hecho de que, en algunos países, la deducción de intereses, regalías y otros desembolsos es permitido sin restricciones cuando el desinatario es residente, pero está restringida, o incluso prohibida, cuando es un no-residente. Esta disposición se incluye en la mayoría de ஓे los CDT de Chile, con algunas excepciones, cris como en los tratados con Canadá, Malasia y \& Noruega. Una cuestión importante sobre la o d deducción de los gastos en el derecho interno chileno, se refiere a sus normas sobre precios de transferencia, que tienen una norma específica sobre las deducciones de intereses. Esta dam: OECD Publishing, 2010). § 33-35.

${ }^{29}$ Ibid. §90.1.

${ }^{30}$ Canadá - Chile CDT, Art. 10 A; Chile - Estados Unidos CDT, Art. 9. regla también se aplica a los pagos de intereses transfronterizos por los EP chilenos, pero no es aplicable a los pagos de intereses internos. A pesar de que esto no es expresamente una regla de subcapitalización, parece que la autoridad fiscal chilena considera que no existe ningún problema con respecto a su aplicación, como resultado de la interpretación del párrafo 74 de los Comentarios al artículo 24(4) del Modelo OCDE, al establecer que dicho párrafo no prohíbe al país del prestatario aplicar sus normas nacionales sobre subcapitalización, en la medida en que sean compatibles con el artículo 9 (1) o 11 (6) del mismo Modelo OCDE. Esta línea de razonamiento del SII es cuestionable y, probablemente, generará conflictos futuros, dado que la reforma tributaria chilena de 2014 sustituyó las reglas de la deducción de los intereses pagados en el extranjero por una nueva que restringe aún más la deducibilidad de dichos intereses.

Otra regla de derecho interno chileno que puede verse afectada por la aplicación del artículo 24(4) del Modelo OCDE es el artículo 31 N$^{\circ} 12$, de la Ley sobre Impuesto a la Renta, que es una de las reglas anti-elusión dirigida a prevenir que los contribuyentes hagan pagos de regalías excesivas o injustificadas. En general, puede entenderse que, en los CDT chilenos que incluyen el artículo 24 (4), el propio tratado limita las normas del citado artículo $31 \mathrm{~N}^{\circ}$ 12. Sin embargo, esto no ha sido declarado expresamente por la autoridad tributaria chilena. Para países que no incluyen esta disposición, Chile ha acordado, en algunos casos, normas especiales sobre la aplicación de esta norma interna, por ejemplo, mediante la reducción de la tasa requerida con el fin de aplicarla (como se establece por ejemplo, en el CDT con Corea), o al aceptar que el requisito establecido en el artículo $31 \mathrm{~N}^{0} 12$, de una tasa de impuesto igual o superior a $30 \%$, se entenderá cumplido cuando el beneficiario efectivo de las regalías sea un residente de otro estado contratante, como se establece, por ejemplo, en el CDT con Dinamarca. 
El Artículo 24 (5) del Modelo OCDE prohíbe a un estado contratante dar un trato menos favorable a una empresa cuyo capital sea propiedad, o esté controlada, total o parcialmente, directa o indirectamente, por uno o varios residentes de otro estado contratante. Esta disposición solo se refiere a la tributación de las empresas - buscando garantizar la igualdad de trato para los contribuyentes que residen en el mismo Estado - y no se aplica a los capitales extranjeros, en manos de los socios o accionistas, quienes pueden tener un trato distinto al aplicado al capital nacional. Chile ha incluido expresamente, en algunos de sus CDT, la redacción del Comentario Modelo de las Naciones Unidas sobre este párrafo del Artículo 24 del Modelo OCDE (United Nations 2011, §5 Commentary to Article 24 (5), por lo que requiere un trato no discriminatorio sólo en comparación con un grupo de terceros países (por ejemplo, en los tratados con Canadá y Brasil). Sin embargo, otros tratados no incluyen esta redacción (por ejemplo, aquellos con España y el Reino Unido). Por lo tanto, parece que la comparación para el análisis de la no discriminación es diferente, dependiendo de la redacción del tratado correspondiente. No existen fallos de la administración tributaria chilena o causas judiciales en esta materia.

El Artículo 24 (6) del Modelo OCDE establece que esta disposición se aplica a los impuestos de cualquier naturaleza o denominación, recaudados por, o en nombre del Estado, sus subdivisiones políticas o autoridades locales, sin limitar su alcance a los impuestos comprendidos en el CDT. Chile se ha reservado su posición respecto del artículo 24 (6) y, por lo tanto, mantiene su derecho de limitar el alcance del artículo 24 a los impuestos comprendidos en el tratado. Algunas excepciones a este principio se encuentran en sus tratados firmados con Estados Unidos y Australia. En su CDT con Estados Unidos, se dice que las disposiciones del artículo 24 se aplican a los impuestos de cualquier naturaleza o denominación, pero sin incluir las leyes tributarias que están en vigor en la fecha de la firma del tratado. En su tratado con Australia, Chile también acordó aplicar el artículo 24 al ya existente Impuesto al Valor Agregado (IVA).

Por último, vale la pena señalar que, en algunos tratados, Chile ha acordado reglas de excepción por las cuales la aplicación del artículo sobre no discriminación se limita sólo a la legislación promulgada después que los respectivos CDT entren en vigor. Esta regla se encuentra, por ejemplo, en los tratados de Chile con Dinamarca y Corea del Sur.

\section{TRIBUTACIÓN COMO EXPROPRIACIÓN}

Los AII chilenos tradicionalmente incluyen una disposición relativa a la protección contra la expropiación, pero la aplicación de impuestos no se califica como una expropiación, en virtud del derecho internacional. Sin embargo, pueden existir casos excepcionales en que la tributación constituya una forma de expropiación indirecta.

Las disposiciones sobre expropiación en APPI chilenos, en general, no proporcionan ningún criterio para distinguir expropiaciones indirectas de medidas regulatorias legítimas. Sin embargo, casi todos los capítulos de inversión de los TLC chilenos, así como el APPI con Uruguay, cuentan con detalladas disposiciones a ese respecto. En estos tratados, expropiación indirecta se define como un acto o una serie de actos de una Parte que tienen un efecto equivalente al de una expropiación directa sin la transferencia formal del título o del derecho de dominio. La determinación de si un acto o una serie de actos de una Parte, en una situación de hecho específica, constituye o no una expropiación indirecta requiere de una investigación factual, caso a caso, que considere entre otros factores:

- el impacto económico del acto gubernamental, aunque el hecho de que un acto o una serie de actos de una parte tenga un efecto adverso sobre el valor económico de una in- 
versión, por sí solo, no establece que una expropiación indirecta haya ocurrido;

- la medida en la cual la acción del gobierno interfiere con expectativas inequívocas y razonables en la inversión; y

- el carácter de la acción gubernamental.

La gran mayoría de estos tratados establecen que, salvo en circunstancias excepcionales, no constituyen expropiaciones indirectas los actos regulatorios no discriminatorios de una parte que son diseñados y aplicados para proteger objetivos legítimos de bienestar público, tales como la salud pública, la seguridad y el medioambiente. ${ }^{31}$

No se han registrado casos o emitido laudos relacionados con AII chilenos donde se analicen las situaciones en que una medida impositiva puede equivaler a una expropiación. Con todo, los tributos que podrían ser considerados como una expropiación en virtud de la mayoría de los APPI chilenos serían aquellos impuestos de carácter confiscatorio, discriminatorios o arbitrarios, con respecto a un Inversionista extranjero, quedando dicha determinación en las manos del tribunal arbitral que conozca la disputa entre el Inversionista y el Estado.

Cabe recordar que, en los TLC chilenos con capítulos de inversión y en el APPI con Uruguay, existen mecanismos de filtro, en virtud de los cuales, mediante un acuerdo de las autoridades tributarias competentes de స్ los estados partes, en el sentido que la medida i tributaria impugnada no tiene carácter expro곡 piatorio, excluiría el uso del arbitraje Inversio$\rightarrow$ nista-Estado, en estos casos.

TRIBUTACIÓN Y LIBRE TRANSFERENCIA DE CAPITAL

Normalmente, los APPI chilenos consideran que cada parte contratante, en cuyo

${ }^{31}$ Esta mención no se encuentra en los TLC de Chile con Japón y Colombia. Si bien tampoco se considera en el TLC Canadá - Chile, la referida decisión de la Comisión de Libre Comercio de ese tratado, también incluye esa declaración. territorio se han realizado Inversiones, permitirá, sin demora injustificada, a los Inversionistas de la otra parte contratante, que realicen la transferencia de fondos en relación con estas Inversiones en una moneda de libre convertibilidad, lo que generalmente incluye el capital y las ganancias (incluyendo expresa o implícitamente los intereses, dividendos y otros retornos); amortizaciones de un contrato de préstamo en relación con la inversión; cualquier capital o el producto de la venta, o venta o liquidación parcial de la inversión; y las indemnizaciones, en caso de expropiación o pérdida. Por regla general, no se consideran restricciones respecto de estas transferencias. ${ }^{32}$

La gran mayoría de los capítulos de inversión de TLC chilenos - salvo el acuerdo con Japón - estipulan que un Estado podrá impedir o retrasar una transferencia a través de la aplicación de manera equitativa, no discriminatoria y de buena fe de su legislación relativa a: la quiebra, insolvencia o protección de los derechos de los acreedores; emisión, comercio u operaciones de valores, futuros o derivados; infracciones penales; cumplimiento de resoluciones o sentencias en procedimientos judiciales o administrativos; ${ }^{33}$ reportes financieros o conservación de registros de transferencias cuando sea necesario para colaborar con el cumplimiento de la ley o las autoridades financieras regulatorias.

En general, la protección de la libre transferencia de intereses, dividendos y ganancias bajo los AII chilenos parece ser más amplia que las disposiciones contenidas en los tratados de inversión modernos, que permiten a los Estados imponer controles de capital que limitan la libre circulación de capitales y pagos en los casos de crisis económica (Kolo; Wälde, 2008). De manera similar, en el derecho de la

\footnotetext{
${ }^{32}$ Los APPI de Chile con Dinamarca, Finlandia, Islandia, Noruega, Nueva Zelanda y la República Checa establecen que el capital sólo podrá ser transferido un año después de que haya ingresado al territorio de la Parte Contratante, a menos que su legislación establezca un tratamiento más favorable.

${ }^{33}$ El Protocolo de la Alianza del Pacífico también agrega expresamente el cumplimiento de los laudos arbitrales.
} 
Unión Europea (UE), ciertas restricciones a los movimientos de capitales se consideran justificadas, como: (i) medidas necesarias para impedir las infracciones a su Derecho y normativas nacionales, en particular en materia fiscal y de supervisión prudencial de entidades financieras, (ii) procedimientos de declaración de movimientos de capitales a efectos de información administrativa o estadística; (iii) y medidas justificadas por razones de orden público o de seguridad pública. ${ }^{34}$ En el caso de Chile, restricciones adicionales a las transferencias, con respecto a dificultades en la balanza de pagos, se encuentran establecidas en los acuerdos de libre comercio de Chile con Australia, Canadá, Colombia, Corea del Sur, Japón, México, y el Acuerdo Suplementario sobre Inversiones con China, así como en el APPI con Uruguay.

Sin embargo, en cada uno de los tratados chilenos de Inversión, Chile ha incluido las reservas correspondientes a las atribuciones del Banco Central (Ministerio de Economía, Fomento y Turismo de Chile, 2015, p. 10), las que incluyen regular la cantidad de dinero y de crédito en circulación, la ejecución de las operaciones de crédito y cambios internacionales, establecimiento de restricciones o limitaciones a los pagos corrientes y transferencias (movimientos de capital) desde o hacia Chile, así como las operaciones relacionadas con ellas, como, por ejemplo, establecer que los depósitos, Inversiones o créditos que provengan o se destinen al exterior estén sujetos a un requisito de reserva (encaje). ${ }^{35}$

Dentro del grupo de los APPI chilenos, solamente los tratados con Cuba, España, Italia, República Dominicana, Rumania, Suecia, Turquía y Vietnam limitan las transferencias de capital y demás relacionadas con la inversión al previo cumplimiento de los deberes impuestos por el Inversionista extranjero.

A la fecha, no existe conocimiento de ningún caso o laudo donde se haya analizado

${ }^{34}$ Tratado sobre el Funcionamiento de la Unión Europea (TFEU), Art. 65.

${ }^{35}$ Ley $\mathrm{N}^{\circ}$ 18.840, Art. 49. una medida gubernamental relacionada con impuestos, respecto de una cláusula de transferencia de capital en un tratado de inversión chilena. En nuestra opinión, un impuesto de retención sobre los dividendos, intereses o beneficios, en la jurisdicción chilena, puede caer en el ámbito de aplicación de las referidas disposiciones de transferencia de capital, si la administración tributaria incurriera en un retraso en evaluar y (o) recaudar dichos impuestos, por lo que podrían considerarse que está impidiendo u obstruyendo la transferencia al exterior del capital o retorno respectivo.

\section{SOLUCIÓN DE CONTROVERSIAS}

\section{Arbitraje Inversionista-Estado}

En todos los APPI y capítulos de inversión de los TLC firmados por Chile, cualquier controversia entre una Parte Contratante y el Inversionista de la otra Parte Contratante debe ser resuelta, si es posible, a través de consultas o negociaciones entre las partes. Este es un requisito previo a la solución jurisdiccional de controversias. Si, transcurrido un tiempo que varía dependiendo de cada tratado (en un rango que va de entre tres a seis meses), no se ha resuelto la diferencia, el inversor puede escoger entre iniciar una demanda ante los tribunales nacionales del Estado receptor o utilizar arbitraje Inversionista-Estado (Polaco Lazo, 2012, p. 224-225). En los AII chilenos, para someter una controversia a arbitraje internacional, el Inversionista puede escoger entre las reglas de arbitraje del Centro Internacional de Arreglo de Diferencias relativas a Inversiones (CIADI) - incluyendo las reglas de su mecanismo complementario y las reglas de arbitraje de la Comisión de las Naciones Unidas para el Derecho Mercantil Internacional (CNUDMI). 


\section{Casos relevantes y debate político}

Chile ha sido demandado en sólo tres casos conocidos de arbitraje Inversionista-Estado ${ }^{36}$, y no ha estado involucrado en un nuevo caso en más de una década, aunque el caso Pey Casado es el más largo en la historia del sistema de arbitraje de Inversiones, ya que se inició en 1998 y continúa hasta hoy en día con respecto a la ejecución del laudo.

A nivel político, no ha existido un debate reciente acerca de los efectos del arbitraje Inversionista-Estado, especialmente respecto de la reducción de la soberanía del Estado, como se ha discutido recientemente en diversos países. Ello se debe probablemente a que Chile ha perdido sólo dos casos, habiéndose cumplido un laudo el año 2007, luego que se perdiera un recurso de anulación (MTD versus Chile) y encontrándose otro pendiente de ejecución (Pey Casado versus Chile).

Tampoco ha existido una discusión pública sobre cómo mejorar la transparencia de los arbitrajes iniciados en virtud de tratados de inversión chilenos. Sin embargo, en los capítulos de Inversiones de los TLC de Chile con Australia, Colombia, Perú y Estados Unidos, el Protocolo de la Alianza del Pacífico y el APPI con Uruguay si incluyen disposiciones para mejorar la transparencia del arbitraje Inversionista-Estado, en los términos que se han explicado precedentemente.

\section{Cláusulas de solución de controversias en} Acuerdos Internacionales de Inversión (AII) y en Convenios de Doble Tributación (CDT)

La principal diferencia con respecto a las disposiciones sobre solución de controversias entre los AII y los CDT chilenos es que todos los tratados de inversión suscritos por Chile estipulan arbitraje Inversionista-Estado

${ }^{36}$ MTD versus Chile; Víctor Pey Casado versus Chile; y Sociedad Anónima Eduardo Vieira versus República de Chile, ICSID Case No. ARB/04/7. y un mecanismo de solución de controversias entre Estados (que también incluye el arbitraje entre Estados), mientras que los CDT chilenos sólo consideran un mecanismo de solución de controversias entre Estados a través de procedimientos de acuerdo mutuo.

De hecho, Chile no ha incluido una cláusula arbitral en ninguno de sus convenios de doble tributación hasta la fecha. Chile siempre ha incluido, en sus CDT, una norma relacionada con la disposición sobre el arbitraje del Acuerdo General sobre el Comercio de Servicios (AGCS), a raíz de los párrafos 88-94 del Comentario al artículo 25 del Modelo de la OCDE. Para los efectos del párrafo 3 del artículo XXII (consulta) del AGCS, los Estados Contratantes acuerdan que, sin perjuicio de ese párrafo, cualquier disputa entre ellos respecto de si una medida está comprendida dentro del ámbito de aplicación de ese tratado puede ser llevada ante el Consejo del Comercio de Servicios, según lo previsto en dicho apartado, sólo con el consentimiento de ambos Estados Contratantes (Madariaga Montes; Yáñez Villanueva, 2012).

Con todo, es poco probable que se presente un caso en el que se le niegue un Inversionista extranjero el acceso al arbitraje Inversionista-Estado, debido a la existencia del PAM prevista en un CDT, ya que ningún tratado de inversión firmado por Chile considera esa posibilidad. Tampoco han existido casos o laudos relacionados con AII chilenos, donde la tributación sobre la indemnización reclamada por el Inversionista, en el arbitraje InversionistaEstado, haya gatillado un problema. Como se explicó anteriormente, Chile no incluye cláusulas de arbitraje en sus CDT suscritos hasta la fecha. Un argumento político o jurídico para excluir el arbitraje de tratados fiscales reside en el hecho de que no está claro si una cláusula de arbitraje puede ser compatible desde el punto de vista constitucional, debido al principio legalista de la tributación consagrado en la Constitución de Chile de 1980. 
El impacto de Base Erosion and Profit Shifting (BEPS) en el arbitraje Inversionista-Estado

Base Erosion and Profit Shifting (BEPS) es el término que se utiliza, en tributación internacional, para designar las estrategias de planificación fiscal utilizadas por empresas multinacionales para aprovecharse de las discrepancias e inconsistencias de los sistemas fiscales nacionales y trasladar sus beneficios a países de escasa o nula tributación, donde las entidades apenas ejercen ninguna actividad económica y eludir, de esta forma, el pago del impuesto sobre sociedades. En ese contexto, la OCDE ha formulado una serie de propuestas o "acciones" para enfrentar este problema. ${ }^{37}$

Teniendo en cuenta la posición actual de Chile con respecto a incluir cláusulas de arbitraje en los tratados de doble tributación, somos de la opinión de que Chile no estaría de acuerdo para incluir dichas disposiciones en sus CDT, a pesar de que varias disposiciones de la Acción 14 de BEPS parecen sugerir que la mejor opción de solución de controversias sería pasar de un PAM a un arbitraje vinculante obligatorio universal. Sin embargo, la acción BEPS 14 reconoce que no existe un consenso entre los miembros de la OCDE en el cambio hacia un arbitraje. ${ }^{38}$ Por lo tanto, se espera que la OCDE promueva la adopción de soluciones complementarias.

La Acción 6 de BEPS también podría tener un impacto en los tratados suscritos por Chile. Al igual que en los tratados tributarios, el abuso de los acuerdos y el "treaty shopping" se han identificado como una de las áreas más importantes de preocupación con respecto a los tratados de inversión (van Harten, 2008). Una de las herramientas más utilizadas para tratar de limitar ambos problemas es la referencia al concepto de un "beneficiario efecti-

37 OECD, "Países en Desarrollo y BEPS," Proyecto BEPS, November 2014, http:/www.oecd.org/ctp/estrategia-fortalecimiento-paises-en-desarrollo.pdf.

${ }^{38}$ OECD, "BEPS Action 14: Make Dispute Resolution Mechanisms More Effective,” December 18, 2014, http://www. oecd.org/ctp/dispute/discussion-draft-action-14-make-dispute-resolution-mechanisms-more-effective.pdf. vo", que trata de evitar el uso indebido de los beneficios derivados de los CDT, sobre todo en los relacionados con los tipos reducidos de impuesto de retención establecidos en los artículos 10 (dividendos), 11 (intereses), 12 (regalías) de los tratados de doble tributación chilenos, así como la reducción acordada en el CDT con Malasia, en la retención en la fuente en los servicios técnicos prestados conforme al artículo 14 de su texto. ${ }^{39}$ Por el contrario, la mayoría de los APPI chilenos siguen la opción tradicional de definición de inversión, como listas generales de bienes y derechos, incluyendo cualquier prestación que tenga valor económico. Los TLC con capítulos de Inversiones han adoptado definiciones más objetivas, que aportan características de la inversión, pero no cuentan con conceptos limitados de esta actividad, la que, en la práctica, queda entregada a la resolución del tribunal encargado de resolver las disputas que se presenten (Arrese Ortíz, 2009, p. 44).

Cláusulas de denegación de beneficios tratan de excluir a las sociedades instrumentales ${ }^{40}$ de los beneficios de los tratados con respecto a los ingresos pasivos (es decir, dividendos, intereses, regalías y otros ingresos), si los Inversionistas de un país no Parte son propietarios o controlan la sociedad instrumental y ella no tiene actividades comerciales sustanciales en el territorio de la Parte conforme a cuya ley está constituida u organizada. ${ }^{41}$ Esta regla de la exclusión se ha incluido en todos los CDT suscritos por Chile, para restringir la aplicación de la reducción de impuestos de retención sobre intereses, dividendos y regalías. En algunos casos, esta regla se ha incorporado como un pár-

${ }^{39}$ Véase Circular $N^{\circ} 57$ emitida por el Director Nacional del Servicio de Impuestos Internos el 16 de octubre de 2009, http://www.sii.cl/documentos/circulares/2009/circu57.htm, vista el 14/08/2015.

${ }^{40}$ De acuerdo con el glosario de términos fiscales de la OCDE, las sociedades instrumentales son aquellas establecidas en relación con un esquema de evasión fiscal, donde la renta es pagada por una empresa hacia el conducto y es luego redistribuida por dicha empresa a sus accionistas, en forma de dividendos, intereses, regalías, etc. Ver http:// www.oecd.org/ctp/glossaryoftaxterms.htm (accessed: 27 August 2015).

${ }^{41}$ Ibid. 
rafo del artículo que se refiere a disposiciones varias, o que se relaciona con el PAM, o el que se refiere a la limitación de los beneficios, o incluso se añadido un Protocolo. ${ }^{42}$ Un ejemplo es el artículo 27 del CDT con Australia, cuya la redacción es la siguiente: "( $\mathrm{t}$ ) las disposiciones de los artículos 10, 11 y 12 no se aplicarán si era el propósito principal o uno de los principales propósitos de cualquier persona interesadas en el asignación de dividendos, intereses o regalías o con la creación o cesión de un derecho o título de crédito respecto de los cuales los dividendos, intereses o regalías se pagan para tomar ventaja de esos artículos por medio de que la creación o cesión”. Sin embargo, sólo algunos tratados de inversión chilenos incluyen estas disposiciones. ${ }^{43}$

Teniendo en cuenta los recientes acontecimientos en el ámbito del derecho tributario internacional y, especialmente, el análisis contenido en la Acción BEPS 6, somos de la opinión de que dicha tendencia puede tener un impacto relevante en la práctica de los tratados de inversión chilenos, impulsando a los Estados parte a revisar y modificar los AII, con el fin de alinear más estrechamente los criterios para la exclusión de las "empresas conducto" de los beneficios contenidos tanto en los CDT como en los AII. Sin embargo, hay que subrayar que el razonamiento que promueve alinear los criterios de exclusión, tanto en CDT

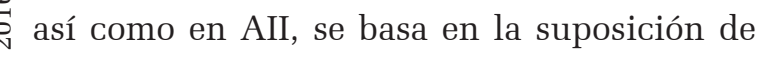
i que sólo los contribuyentes tratan de evitar las normas fiscales, mientras que los gobier$\therefore$ nos son siempre jugadores leales que respetan \& las normas nacionales e internacionales. Sin 될 embargo, la experiencia en varios países dea muestra todo lo contrario. Algunos gobiernos oे utilizan subterfugios para eludir las disposiciones de los CDT, privilegiando la aplicación de normas nacionales. En este contexto, parece conveniente que una disparidad de crite${ }^{42} \mathrm{SII}$ (n 39).

${ }^{43}$ Se trata de los TLC con Canadá, Corea del Sur, Estados Unidos, Japón, Australia, Panamá, México y en el Protocolo de la Alianza del Pacífico. rios siga existiendo, ya que proporciona a los contribuyentes algunas medidas de protección contra prácticas gubernamentales abusivas.

\section{CONCLUSIÓN}

Como se advierte a lo largo de este artículo, hay un paralelismo notable entre la suerte que han corrido los Tratados de Inversión y los Tratados de Doble Imposición suscritos por Chile. Y no es raro que así sea, teniendo en cuenta que tanto los APPI como los primeros CDT suscritos por Chile formaron parte de una misma estrategia de inserción de nuestro país en la economía global, que tuvo lugar a principios de la década de 1990.

Al igual que sucede en materia de protección a las Inversiones, en el ámbito de la tributación internacional, puede observarse una evolución en la política de negociación de tratados, que es fruto de la experiencia adquirida por los equipos negociadores y también es resultado de la retroalimentación entregada por las autoridades administrativas y que proviene de la aplicación práctica de dichos instrumentos.

En el ámbito de la protección a las Inversiones e Inversionistas, esto significó migrar desde la suscripción de APPI, cuyo contenido es más breve y simple, a la negociación de capítulos especiales en el marco de TLC, con cláusulas extensas y complejas. En cambio, en el ámbito de la tributación internacional, la evolución no se manifestó en el tipo de instrumentos suscritos, pues Chile continuó negociando sólo CDT (con la excepción de algunos acuerdos administrativos complementarios de intercambio de información tributaria), pero sí se evidenció, en el contenido de los mismos, mediante la inclusión de cláusulas más extensas (como en el caso de Protocolos o Normas Misceláneas) o más complejas (como sucede con las cláusulas de limitación de beneficios - LOB).

Dicha evolución también puede analizarse considerando a ambos tipos de tratados 
como instrumentos complementarios, en cuanto ambos tienen por objeto proteger o beneficiar a Inversionistas e Inversiones, pero cuyos ámbitos de aplicación son específicos y diferenciados. Por este motivo, las consideraciones de mayor complejidad e interés surgen al detectar y evaluar hipótesis de superposición o conflicto entre ambos tipos de instrumento, así como las soluciones que se han ido planteando para delimitar la aplicación de unos y otros, especialmente en lo referido a la resolución de conflictos entre un Estado y un Inversionista.

En este último sentido, los tratados de inversión parecen haber asumido la mayor parte del esfuerzo por delimitar su ámbito de aplicación, a fin de evitar colisiones o superposiciones con los CDT. Es probable que algo similar ocurra en los próximos años desde la perspectiva de los CDT, teniendo en cuenta la ambición sin precedentes de la iniciativa BEPS por regular y controlar la tributación internacional mediante dichos instrumentos.

Recebido para publicação em 15 de outubro de 2015 Aceito em 21 de novembro de 2015

\section{REFERENCIAS}

ARRESE ORTÍZ, D. Modelo chileno de Tratados sobre Inversión. 2009. Available at: http://www.tesis.uchile.cl/ handle/2250/106982. Accessed: August 15, 2015.

EXCHANGE OF TAX INFORMATION PORTAL. Chile. 2015. Available at: <http://eoi-tax.org/jurisdictions/ CL\# agreements>. Accessed: August 14, 2015.

GREIBER BETSABEL, P.; OCAMPO MOSCOSO, L.F; SEGUEL MALAGUEÑO, L. Justicia tributaria y delegación de facultades jurisdiccionales: análisis de la jurisprudencia reciente del Tribunal Constitucional. Sentencias Destacadas, 2007, p. 235-274.

KOLO, A.; WÄLDE, Thomas. Treatment of Capital Transfer Restrictions. In: August Reinish (ed.) Standards of Investment Protection, Oxford; New York: Oxford University Press, 2008, p. 205-243.

MADARIAGA MONTES, J; YÁÑEZ VILLANUEVA, F. Chile. En: The impact of the OECD and UN model conventions on bilateral tax treaties, de Michael Lang, Pasquale Pistone, Josef Schuch y Claus Staringer, 232-260. Cambridge University Press, 2012.

MEREMINSKAYA, E. La cláusula paraguas: lecciones de convivencia para los sistemas jurídicos. Revista Internacional de Arbitraje, Julio-Diciembre 2009, p.13-59.
MINISTERIO DE ECONOMÍA, FOMENTO Y TURISMO DE CHILE. Informe Comisión Asesora Transversal para la Nueva Institucionalidad en Inversión Extranjera. Santiago: Comité de Inversiones Extranjeras, 2015, http://www. economia.gob.cl/wp-content/uploads/2015/01/INFORMEINV-EXTRANJERA.pdf

ORGANISATION FOR ECONOMIC COOPERATION AND DEVELOPMENT (OECD). Joint Statement By the Early Adopters Group. 10 2014. Available at: http://www.oecd. org/tax/transparency/AEOI-early-adopters-statement.pdf. Accessed: 02/2016.

. Jurisdictions Participating in the Convention on Mutual Administrative Assistance in Tax Matters. 0802 2016. Available at: http://www.oecd.org/ctp/exchange-oftax-information/Status_of_convention.pdf.

. Model Tax Convention on Income and on Capital. 15 July 2014. Available at: http://www.oecd.org/ctp/treaties/ oecd-model-tax-convention-available-products.htm.

PARK, W. W. "Arbitrability and Tax." In Arbitrability: International and Comparative Perspectives, by Loukas A. Mistelis and Stavros L. Brekoulakis, 179-206. Kluwer Law International, 2009.

Arbitration and the Fisc: NAFTA's "Tax Veto". Chicago Journal of International Law, v. 2, n. 1, 2001), p. 231.

POLANCO LAZO, R. Legal Framework of Foreign Investment in Chile. 18 Law \& Business Review of the Americas, 2012, p. 203-231.

QURESHI, A. H. Coherence in the Public International Law of Taxation: developments in International Taxation and Trade and Investment Related Taxation." 10 Asian Journal of WTO \& International Health Law and Policy, 2015, p. 193-222.

SALOMON, C.; FRIEDRICH, S. How Most Favoured Nation Clauses In Bilateral Investment Treaties Affect Arbitration. Practical Law, 2013, p. 9.

SERVICIO DE IMPUESTOS INTERNOS. Convenios Tributarios Internacionales. 1505 2015. Available at: $<$ http://www.sii.cl/pagina/jurisprudencia/convenios. htm >. Accessed: 05, 15, 2015.

UNITED NATIONS CONFERENCE ON TRADE AND DEVELOPMENT (UNCTAD). Chile - Bilateral Investment Treaties (BITS). $07 \quad 10$ 2015. Available at: $\quad<$ http://investmentpolicyhub.unctad.org/IIA/ CountryBits/41\#iiaInnerMenu>. Accessed: 10, 07, 2015).

-. Chile Model BIT. 1994. Available at: <http:// investmentpolicyhub.unctad.org/Download/ TreatyFile/2841>. Accessed: 10, 07, 2015).

Expropriation: A Sequel. New York: United $\overline{\text { Nations }}, 2012$.

UNITED NATIONS. "Model Double Taxation Convention between Developed and Developing Countries." 2011. Available at: < http://www.un.org/esa/ffd/documents/UN Model_2011_Update.pdf $>$. Accessed: August 15, 2015.

VANDERBRUGGEN, E. "Investment Arbitration in Tax Matters: Some Thoughts on Selected International Case Law." 25th Annual Conference of the Australian Tax Teachers Association. Auckland: <http://www.nzica.com/ Training-and-events/CPD-policy-and-online-log/2013-TaxConference-material.aspx? $\mathrm{p}=1,2013.1-34>$.

VAN HARTEN, G. Investment Treaty Arbitration and Public Law. Oxford: Oxford University Press, 2008.

YANNACA-SMALL, K. Interpretation of the Umbrella Clause in Investment Agreements. Working Papers on International Investment No. 2006/3, Paris: Organisation for Economic Cooperation and Development (OECD), 2006. 


\section{THE RELATIONSHIP BETWEEN INVESTMENT AND DOUBLE TAXATION TREATIES: the Chilean case}

\author{
Rodrigo Polanco Lazo \\ Felipe Yáñez Villanueva
}

This article examines the relationship between investment and double taxation treaties, considering that in the current evolution of both types of agreements their provisions may have superimpositions on aspects such as safety standards, transparency, national treatment, a clause for most favored nation, expropriation and capital transfers. Taking the example of the treaties signed by Chile, this study examines the consequences of the transpositions of both agreements, from the point of view of their dispute settlement mechanisms, such as with regard to the normative hierarchy of conflict between these two types of treaties. Similarly, it analyzes the multilateral initiatives that affect both categories of agreements, such as the Base Erosion and Profit Shifting (BEPS).

KEYwORDS: Foreign investment. Bilateral investment agreements. Double taxation treaties. BEPS. Chile.

\section{LA RELATION ENTRE LES TRAITÉS D'INVERSION ET LES TRAITÉS DE DOUBLE IMPOSITION: le cas du Chili}

Rodrigo Polanco Lazo

Felipe Yáñez Villanueva

Cet article analyse les liens qu'il y a entre les traités d'investissement et les traités de double imposition en considérant que, dans l'évolution actuelle des deux types d'accords, leurs dispositions peuvent présenter des superpositions concernant des aspects tels que les normes de protection, la transparence, le traitement national, la clause de la nation la plus favorisée, l'expropriation et les transferts de capitaux. En prenant l'exemple des traités signés par le Chili, ce travail évalue les conséquences de la transposition des deux accords, du point de vue de leurs mécanismes de règlement des différends ainsi qu'en ce qui concerne les conflits de hiérarchie normative entre ces deux types de traités. Il en est de même quant à l'analyse des initiatives de type multilatéral qui touchent les deux types d'accords, tel que la Base Erosion and Profit Shifting (BEPS).

Mot-CLÉS: Investissement étranger. Accords bilatéraux d'investissement. Traités de double imposition. BEPS. Chili.

Rodrigo Polanco Lazo - Advogado. Doutor em Direito. Mestre em Direito. Professor Assistente do Departamento de Direito Econômico da Faculdade de Direito da Universidade do Chile e acadêmico e pesquisador do Instituto Mundial do Comércio (WTI) da Universidade de Bern.

Felipe Yáñez Villanueva - Advogado. Mestre em Direito Tributário na Universidade de Colônia, Alemanha. Professor de Direito Tributário da Universidade de Los Andes (Chile) e Diretor de tributação corporativa em Mazars Chile. 